\title{
The Eclipse of the Uncertainty Concept in Mainstream Economics
}

\author{
Geoffrey M. Hodgson* \\ Published in the Journal of Economic Issues, March 2011. \\ KEY WORDS: uncertainty, probability, prediction, Frank Knight, John Maynard Keynes, \\ formalization of economics.
}

JEL classification: A10, B22, B50, E12,

\begin{abstract}
This paper examines the decline in use of the Knight-Keynes uncertainty concept in mainstream economics. Using electronic archives, it shows that the frequency of its appearance in leading journals of economics has fallen rapidly from the 1950s. As well as to the declining popularity of Keynesian ideas since about 1970, the decrease in this use of the uncertainty concept is additionally related to the increasing mathematical formalization of economics and to the prevalence of a positivist emphasis on prediction. Some possible causes of this formalization are examined. Finally the essay discusses the prospects for a broadening of economics within universities, beyond a relatively narrow preoccupation with predictive formalism and including a reinvigorated Keynesianism.
\end{abstract}

* Research Professor, University of Hertfordshire Business School, De Havilland Campus, Hatfield, Hertfordshire AL10 9AB, UK. Website www.geoffrey-hodgson.info. 
The limitations of formal modeling are underlined by Keynesian the concept of uncertainty. ${ }^{1}$ Readers of this journal are fully aware that the concept acquired a special meaning in the work of Frank H. Knight (1921) and John Maynard Keynes (1936, 1937). Despite some detailed differences (which we do not need to dwell on here - see Hoogduin 1987), both authors used the terms uncertainty and uncertain to refer to events regarding which no probability was calculable (Davidson 1972, 1991, Lawson 1985, Runde 1998, Cornwall and Cornwall 2001). Knight (1921, pp. 19-20) saw risk as "a quantity susceptible of measurement," while uncertainty was "unmeasurable" and "non-quantitative." As Keynes (1937: 217) put it, uncertainty applies to situations where there is "no scientific basis on which to form any calculable probability whatever." Just as for Knight (1921) the existence of real-world uncertainty helps to explain why business firms exist, Keynes (1936) argued that uncertainty is a principal reason for the demand for liquidity in a money economy. Uncertainty thus becomes a vital concept in explaining at least two key economic institutions.

Yet mainstream economists have mostly abandoned the concept of uncertainty. This paper examines the rise and fall of the Knight-Keynes uncertainty concept from the 1920s and 1930s until today. This concept is chosen for another important reason: it is central to Keynes' economics, but by definition it resists increasingly fashionable quantification and eschews prediction. In this respect the uncertainty concept differs from other Keynesian ideas such as the multiplier. Bibliometric analysis suggests that the frequency of the appearance of Keynesian uncertainty in leading mainstream journals of economics has declined rapidly from the 1950s. It is likely that this decline is related to the increasing mathematical formalization of economics, the particular emphasis on mathematical models that yield predictions, and the fall in popularity of Keynesian ideas from the 1960s. Some possible causes of these shifts are examined.

It is argued that while many Keynesians have embraced mathematical models, the analytical core of Keynes's theory - involving the uncertainty concept - places limits on the type, predictive capacity and extent of modeling employed. Discussion of these limits is unfashionable in mainstream economics today.

The following section outlines the bibliometric methodology and results. The decline in citations to works by Keynes and Knight is also depicted. The section after that considers the negative correlation between the decline in the uncertainty concept and the increasing mathematical formalization of economics. A further section considers some causal underpinnings of the two developments, in terms of the culture and institutions of academic economics. The penultimate section considers the prospects for renewed post-Keynesian ${ }^{2}$ economics in the light of this analysis.

\section{The Rise and Fall of the Uncertainty Concept}

What has been the fate within mainstream economics of the Knight-Keynes concept of uncertainty since its appearance? The following methodology was adopted to gauge the frequency of appearance of the uncertainty concept in leading mainstream (Anglo-American) journals of economics. Journals were selected that had emerged no later than 1940. Table 1 shows the ten journals of economics that come into this category.

Without doubt the uncertainty concept has enjoyed more exposure in heterodox journals such as the Cambridge Journal of Economics, the Journal of Post-Keynesian Economics, and the Journal of Economic Issues. But the point of this analysis is to examine the usage of the uncertainty concept in mainstream journals; these have much wider circulation and influence. 
A major problem in gauging the frequency of the Knight-Keynes concept of uncertainty is that same term is widely used by many mainstream theorists to refer to situations where a probability can be calculated. Consequently, a search was made for articles in the nine journals where not only the words "uncertain" or "uncertainty" appeared but also contained the names "Keynes" or "Knight". 3

Table 1 About Here (including endnote 4)

Figure 1 About Here

Having determined the number of articles satisfying this condition, their frequency was calculated by dividing by the total number of articles published in the ten journals in each decade. The results are shown in Figure 1.

Of course, bibliometric techniques of this kind have important limitations. Here the search criterion is relatively crude and it cannot exclude cases where, for example, Keynes or Knight are mentioned but a different concept of uncertainty is used. It would also exclude cases where "uncertain" was used in the sense of no calculable probability but mention was made of neither Keynes nor Knight. There are other possible types of false negative or false positive identification. But no obvious example of these exceptions was discovered by brief inspection of the numerous articles involved. ${ }^{5}$ Given these caveats, the claim here is that this particular search helps to gauge the changing impact of the Knight-Keynes uncertainty concept on the mainstream, and their relation to other related developments in mainstream economics.

Note how in particular - by this measure - the use of the Knight-Keynes uncertainty concept rises dramatically from 1920 and reaches a peak of about seven per cent of articles in the 1940s, after the publication and widespread impact of the General Theory. It then declines dramatically from the 1950 s to the 1960 s, reaching levels between three and four percent. A further decline follows the 1980s and is sustained into the most recent period, to reach a low level of about two percent.

As a comparative yardstick, the figure shows the percentage of articles citing the multiplier - by contrast a quantifiable concept that is also prominent in Keynesian models. Its usage is greater and its decline is not as precipitous as that for uncertainty. But this conclusion must be qualified by noting that no Boolean condition was imposed in this case. It was omitted because the multiplier is a distinctively Keynesian concept and does not suffer the same profound ambiguity as the concept of uncertainty. ${ }^{5}$ If the number of articles citing both Keynes and the multiplier is assessed, then the absolute level falls and the decline is more precipitous. ${ }^{6}$ It seems that it became acceptable for economists to write about the multiplier without mentioning Keynes. ${ }^{7}$ By contrast, it is generally necessary to mention Knight or Keynes to establish an uncertainty concept distinguishable from risk. But again we must be aware of the limitations of the methodology here. 
This figure also depicts the even-more dramatic decline in citations to Keynes in the ten journals since the 1940s. ${ }^{8}$ Citations to Knight have never reached so high but have been in steady decline since the 1930s.

Rather surprisingly, the percentage citations to Keynes in the ten journals begins to decline in the 1950s, when a form of Keynesianism was still dominant in the profession. There may be several reasons for this that are difficult to disentangle and assess. First, it may be due to a diminishing general propensity to cite past authors, correlating with the falling post-war status of the history of economic thought as a sub-discipline. (Similar arguments may help explain the habit of some economists to use the multiplier without citing Keynes.) Second, this early decline may also be a result of the extraordinary interest in Keynes's ideas in the 1940s, in the specific context of the Second World War, its aftermath, and the death of Keynes in 1946: the higher you rise the harder you fall. Third, interest shifted from the "economics of Keynes" to a form of "Keynesianism" (Leijonhufvud 1968) comprising IS-LM analysis, multiplieraccelerator and other formal models - and generally excluding uncertainty in the Keynesian sense. As the model became supreme, the person was deemed less relevant.

It is difficult to use bibliometric techniques to gauge the overall popularity of Keynesian ideas, but the declining pattern of citations to Keynes is otherwise consistent with the increasing attack on Keynesianism from Chicago and elsewhere, which became significant in the 1960s and gathered enormous force in the 1970s. The contention here is that Keynesianism faced an attack on several fronts: ideological, theoretical and mathematical.

A full analysis of the tangled complexities of this battle is beyond the scope of this essay. Instead I suggest that an increasing and excessive emphasis on ostensibly predictive formal models was one of several reasons for the declining use of the Keynesian or Knightian concept of uncertainty. It is also true that this concept suffered the general fate of Keynesian theory, and a decline also due to theoretical and ideological opposition to Keynesianism. The purpose of this essay is to focus on one part of this complex story that has been previously much less explored.

\section{The Formalization of Economics and the Decline of the Uncertainty Concept}

Consider the relationship between the post-war decline of the use of the uncertainty concept in mainstream economics and the increasing formalization of economics. ${ }^{9}$ Although the roots of formalization go back as far as the deductivism of David Ricardo and the impact of the marginal revolution after the 1870s, it was not until the Second World War or after that mathematics began to dominate the discipline.

This is confirmed by a study carried out by George J. Stigler, Stephen M. Stigler and Claire Friedland (1995) of the impact of mathematics in four leading journals. ${ }^{10}$ Before the $1920 \mathrm{~s}$, verbal expositions dominated more than 90 per cent of the articles published in these journals. After 1940, predominantly verbal exposition fell steadily to about 33 per cent of articles in the 1960s. By the early 1990s, over 90 per cent of the articles in the leading and enduring journals were dominated by algebra, calculus and econometrics (Stigler et al, 1995: 342). After similar studies of the literature, Roger Backhouse (1998), Mark Blaug (1999, 2003) and E. Roy Weintraub (2002) argue that the "formalist revolution" in economics was consolidated in the late 1950s. This transformation was given some impetus by the long report to the American Economic Association by Howard R. Bowen (1953) that called for more extensive training in mathematics at graduate level. 
This timing corresponds closely with the decline of the uncertainty concept, as illustrated in Figure 1. One major causal link is obvious: it is difficult to fit (non-quantitative) uncertainty into a model. It is a concept thus banished from mainstream economic theory. As Robert E. Lucas (1977: 15) wrote: "In cases of uncertainty, economic reasoning will be of no value." This is redolent of Kenneth J. Arrow's (1951: 417) earlier discussion of Knight's uncertainty concept and his conclusion that without measurable probabilities "no theory can be formulated for this case." Both authors then upheld that "economic reasoning" and "theory" were quantitative. ${ }^{11}$ In this context, economists pushed aside Keynesian or Knightian objections that uncertainty was incalculable. They either ignored the unquantifiable concept or gave uncertainty a subjective and quantifiable interpretation.

Uncertainty does not mean that Keynesians have to abandon mathematical models. But they are faced with a choice: either to adopt models with grand predictive claims where the concept of uncertainty is downplayed, or to limit the use of modeling and inhibit the predictive claims. Keynes himself was firmly in the latter camp. ${ }^{12}$

For much of the twentieth century, economics has been captivated by a vision of science where predictability has been the paramount aim. Economists often react to unpredictability with angst or even panic. When some results in monopoly theory were revealed as unpredictable, John Hicks (1939: 83-4) complained that "the stability conditions become indeterminate; and the basis on which economic laws can be constructed is therefore shorn away." Hicks saw this as having "a very destructive consequence for economic theory." Theory and formalization became virtually synonymous, to stand or fall together on the matter of predictive success. Subsequently Milton Friedman (1953) elevated prediction as the supreme goal for economists in his classic and highly influential article.

Contemporary economics retains this devotion to model-based prediction. When prediction is thwarted within a particular mathematical approach, then often that type of approach falls out of favor. This is confirmed by considering developments in mathematics that show that predictability is sometimes unobtainable. When chaos theory emerged in the 1980s and demonstrated that outcomes in non-linear systems are often unpredictable, economists met this new mathematics with a significant flurry of interest. ${ }^{13}$ Furthermore some Keynesians saw this as an opportunity to embrace a form of modeling that was consistent with their ideas (Day 1983, Day and Shafer 1985, Rosser 1991). But mainstream discussion of chaos theory has since waned, and it has never been given the attention warranted by the ubiquity of nonlinearities in the real world. This is apparent in the bibliometric data in Figure 2. After 1995 the frequency of the term "chaos theory" in all JSTOR journals in economics reached a low level. Mainstream economics is not simply focused on mathematical models; it elevates those models that purport to yield predictions and downplays those that show that our powers of prediction are limited.

For example, a model of the business cycle developed by Richard Goodwin $(1972,1990)$ involves non-linear dynamics where (with some parameter values) outcomes are highly sensitive to initial conditions, thus eroding its predictive capacity. Despite its reputable mathematics and relatively appealing formal characteristics, the Goodwin model has remained rarely cited in leading journals since its inception. To date since its initial publication it has received only eleven citations to articles in the ten economics journals in Table 1. It seems that anything that gets in the way of the Holy Grail of model-based prediction is pushed aside, even when it is has a strong mathematical component. 
Figure 2 About Here

Neither has the "complexity revolution" yet shifted mainstream economics from its predictive goals. Although there has been significant discussion of complexity in mainstream journals, it has not yet shaken the belief that the main aim of economics is to build models that yield useful predictions. Rather than look real-world complexity in the face, economists have remained in an artificial world of much simpler models, partly to maintain the rhetoric of prediction. As yet, established techniques for dealing with complexity, such as agent-based modeling and Kauffman-type $N K$ models, are generally rare in leading mainstream journals.

To recapitulate, the decline of the uncertainty concept coincides with the inverse process of a rising mathematical formalism in mainstream economics that was directed toward the task of prediction. Partly because of its intrinsic non-quantifiability, the Knight-Keynes uncertainty concept declined in significance. But the evidence suggests that it is not only the non-quantifiability of uncertainty that has been a problem for the mainstream. Brief consideration here of other ideas such as chaos theory and complexity suggests that the additional problem of unpredictability is an additional reason why uncertainty is shunned. ${ }^{14}$ Chaos theory and complexity involve mathematical formalism without generally leading to adequate predictions, and they have not yet had a major impact on economics.

Uncertainty is not only unquantifiable but it restricts precise prediction. It is thus prevented by a double-lock from entry into the mainstream. Mainstream economics would have to abandon both its obsession with formalization and its primary goal of prediction for the door to be opened. ${ }^{15}$ If mainstream economics followed the advice of David Colander (2000) and others, and retained formalism but entered the often unpredictable world of complexity, then this alone would not re-admit uncertainty. ${ }^{16}$ But the downgrading of prediction may itself raise questions and concerns concerning the role of models. In contemporary mainstream economics the issues of formalism and predictability remain intimately connected.

\section{The Culture and Institutions of Academic Economics}

The cults of formalism and prediction have spread much wider than economics itself. The impetus for quantification has ancient historical sources (Crosby 1998). Philip Mirowski (1989) and others have argued that the emulation of the apparent predictive success of other sciences such as physics from the nineteenth century has led to the adoption of a particular kind of formalism within economics. The influence of positivism is also held to be responsible for an increased emphasis on prediction-yielding models in several sciences. Philosophers of science in general (Quine 1953, Bhaskar 1975) and of economics in particular (Caldwell 1982, McCloskey 1994) have long heralded a post-positivist era where prediction is no longer a supreme goal, but this shift of view is not yet reflected in the day-to-day practice in several natural and social sciences. ${ }^{17}$

Arguably, major reasons for the persistence of positivism and its emphases on quantification and prediction are found within the institutionalized practices of academia itself. As university sectors within developed countries have greatly expanded since the 1950s, university researchers have been under increasing pressure to justify their existence 
and their receipt of financial support from the public purse and elsewhere. The positive benefits of this expansion are partly offset by a consequent distortion of research. Academics are asked to seek out grants where research has often to be justified in terms of some practical or predictive value. Research that seeks primarily to explain, and makes lesser claims to predict, is less attractive for those on grant-awarding bodies with missions to promote research that proffers immediate practical consequences.

Global pressures have impacted on modern universities in the twentieth century and led to significant overall changes in the nature of teaching and research. But the ways in which different disciplines have evolved in response to these pressures express varied histories and dynamics. Particularly with formalism in economics, there are strong elements of positive feedback and path dependence. But we also have to understand the general academic context in which these changes take place.

Before the Second World War, universities were reserved for a rich or intelligent minority. Despite pressures from business and religious institutions, they managed in places to dispense a relatively broad education and maintained an ethos for the pursuit of truth. This changed in most developed countries sometime after the Second World War. Especially since the 1960s, the university has become an institution much more oriented to specialist professional training under the behest of business corporations.

Thorstein Veblen (1918) observed some of the early stages of this evolution within universities long ago. Others (Callahan 1962, Bloom 1988, Lutz and Field 1998, Kirp 2003, Greenberg 2007) have charted the post-war decline of broad and questioning inquiry, and the rise of narrower forms of professional training targeted at the needs of business. Students are less encouraged to pursue big questions. They are urged instead to acquire qualifications that signal skills that can be hired on the jobs market.

Together these forces eroded enclaves of broad liberal education, vastly expanded specialized professional training, led to explicit requirements to account for the economic value of university research, and promoted the increasing use of league tables and formalized research assessments to pressure academics to publish research in acknowledged outlets.

These background institutional and cultural forces have impacted upon disciplines in different ways. Economics suffered in a peculiar manner because it had established a type and degree of formalism that allowed research output to be assessed principally in terms of mathematical elegance and predictive claims. Economists were judged and became employable for their aptitudes for statistical analysis or predictive models.

There is a conservative trend in any science. Robert J. Shiller (2008) writes of the herding of economists around conventional views for fear of bucking the trend. This problem is especially severe in a discipline as monolithic as economics, dominated as it is by relatively few theoretical paradigms and approaches, with the control of journals and other resources concentrated in relatively few academic institutions (Hodgson and Rothman 1999). The oligopolistic distribution of power within the discipline affects both publications and funding. Papers of a less technique-driven nature, or those that employ techniques that differ from those that prevail in the mainstream, are more difficult to publish in prestigious journals; grant applications that are bereft of models or predictive claims are unlikely to be approved by refereeing economists; and candidates without a good modeling portfolio are unlikely to be promoted. In a process of cumulative causation, the cult of prediction-oriented technique feeds on itself. There is a peacock's tail process of ongoing selection and replication, where output is judged on its mathematical magnificence rather than its verisimilitude or practical usefulness. ${ }^{18}$ Jerry Ravetz (1994-95) thus concludes that economics has become "an elite folk 
science." One particular feature of this transformation has been the exclusion of the concept of uncertainty.

\section{Prospects for a post-Keynesian Economics}

This rather pessimistic line of argument raises the question of the prospects of revival of the kind of Keynesian or institutional economics. On the other hand, do recent economic events provide a window of opportunity? The world financial crash of 2008 signaled the most serious global economic crisis since the Great Depression of the 1930s. Just as John Maynard Keynes is remembered for his critique of the economic theories and policies of his day, critics of mainstream economics may wonder if the latest crisis will help to revive the discipline by exposing the limitations of current economic theory and policy.

While economics as a discipline evolves slowly, the ideological mood has changed rapidly. The financial crisis of 2008 led to remarkable retractions among world leaders of previous commitments to lightly-regulated financial markets. The market is no longer seen as the solution to every problem. After decades of neglect, journalists and politicians have pointed to the relevance of Keynesian ideas. ${ }^{19}$

These changes in ideology among world politicians create a different environment for economists. But as yet there are no strong shifts of opinion or practice among academic leaders of our profession. We search with difficulty in departments of economics for similar conversions or recantations. ${ }^{20}$ Despite the appeals of many, and the energetic appeals of Keynes-leaning Nobel Laureates Joseph Stiglitz and Paul Krugman, there is little sign that the majority of economists are returning to the classic texts in general or Keynes in particular. Mainstream economists explicitly admit that they see little warrant or value in reading the sages of the past (Dasgupta 2002). Despite the biggest global economic crash since the 1930s, the preoccupation with mathematical technique remains, and the signs are of "business as usual" (Cohen 2009).

History gives us little further grounds for optimism. Although the Great Depression led to the rise of a form of Keynesian economics, it also helped to provide an impetus for more extensive use of mathematics in economics. A younger generation of economists, impatient with the failure of the older economists to find solutions, turned to mathematical models as well as the Keynesian doctrine. ${ }^{21}$ The 1930s "revolution" in economic thought promoted not only a relatively simplified version of Keynesianism but also it was led by a younger generation of economists including Paul Samuelson and others that promoted formal economic models. They emphasized those parts of Keynesianism that could be modeled, and were impatient with the equivocal ruminations of older economists that had buried themselves in historical facts in their attempts to understand capitalism's laws of motion.

The attraction of this more mathematical approach was partly its technocratic lure, and partly because it proposed apparent solutions to the urgent problem of the day. It appeared that increasing a variable called $G$ could alleviate the problem of unemployment. Although Keynes himself warned of the limitations of mathematical technique in economics (Moggridge, 1992: 621-3), he was championed by a younger generation who saw mathematics as a tool for the construction of predictive models.

Although the Great Depression established a Keynesian macroeconomics, it also gave impetus to the process of mathematical formalization that gradually accelerated in the postwar period. Although Keynes fell out of vogue from about 1970, and the character of 
mainstream economics has changed in other respects in recent decades, its obsession with technique over substance remains.

In 1988 a Commission set up by the American Economic Association examined the state of graduate education in economics in the US. The Commission expressed its fear that "graduate programs may be turning out a generation with too many idiot savants skilled in technique but innocent of real economic issues" (Krueger 1991: 1044-5). Alan Blinder (1990: 445), a member of the Commission, commented:

Both students and faculty find economics obsessed with technique over substance ... the many macro and micro theory exams the Commission examined . . . tested mathematical puzzle-solving ability, not substantive knowledge about economics . . . Only 14 percent of the students report that their core courses put substantial emphasis on "applying economic theory to real-world problems."

Since the 1988 Commission there has been a sideline litany of complaints from leading members of the profession, including Nobel Laureates such as Wassily Leontief (1982), Ronald Coase (1997) and Milton Friedman (1999). But David Colander (2009) lamented that none of these prominent warnings "had any effect on US graduate economic education." As Mark Blaug (1998: 45) wrote pessimistically: "We have created a monster that is very difficult to stop."

Despite the post-2008 rise in popularity of Keynes's ideas among politicians, none of this additional information gives hope for a revival from within mainstream economics of the kind of broad-minded thinking, grounded in a wider erudition, which was typical of Knight, Keynes and others in their time.

As Paul Davidson (1972) and others have pointed out, the form of Keynesianism that enjoyed its heyday from the 1940s to the 1960s did not place Keynes's uncertainty concept at the centre of the analysis. Yet some Keynesians have fully acknowledged uncertainty while retaining a role for formal models. A seminal essay by Jan Kregel (1976) is an example of this genre, and it explicitly faces the problem of modeling in the face of Keynesian uncertainty.

Note that while establishing a legitimate heuristic and partial role of models in this context, Kregel abandons all general predictive aims. He echoes Keynes's claim that in "it was in the nature a monetary economy that the future could not be known" (Kregel 1976: 221). Kregel indicates that is possible to formulate formal models of an environment of uncertainty, but these are for tracking particular causal interactions rather than yielding predictions. According to Kregel, this is the type of modeling implied by Keynes in the General Theory. Yet Kregel's argument suffered the fate of the Keynesian movement as a whole. This suggest that it is not the quest of formal modeling as such that accounts for the decline of Keynesian ideas such as uncertainty, but the belief that the primary purpose of models is prediction, and a growing obsession with formal technique over substance which has led economists to ignore or downplay the realities of a modern capitalist economy.

Neither crises nor failures of prediction necessarily impel economists in the direction of realism. One likely reaction to the current downturn is that we should try harder to develop better models. Perhaps we should. But if these models are primarily designed to yield correct predictions, then their success will be highly limited. We must also learn the vital lesson that models on their own are never enough, and prediction is sometimes impossible even with the best of models. We need better models, but their primary aim is to aid causal explanation.

Economists need to appreciate the limitations of modeling. These limitations are generic and result from the intractabilities of uncertainty, complexity and system openness in the real 
world. In such a context a primary role for models is heuristic rather than predictive. Also a better understanding of our current predicament must also come from a much fuller appreciation of both economic history and the history of ideas. What is required is a wholesale revitalization of the culture within the economics profession.

\section{Conclusion}

The concept of uncertainty is not only central to Keynesian economics, but also its degree of prevalence is an indicator of the scientific culture of the economics profession. Its decline in usage is one litmus test among others of a culture change within mainstream economics over the last half century.

A primary conclusion of the analysis here is that the decline of the Knight-Keynes concept of uncertainty in mainstream economics is due to a complex of factors, including the ongoing fashion for models that purport to yield predictions, as well as ideological and doctrinal attacks on Keynesianism itself. It is notable that mathematical models that are unreliable for prediction - including non-linear and chaotic dynamics - have also proved unpopular. The problem with mainstream economics is not simply its obsession with technique over substance, but also the limited and unsuitable types of formalism that are adopted. This essay is not a call for the banishment of all formalism from economics, but for the adoption of mathematical approaches that are more suitable, and predictive claims that are more modest, in the context of a much broader and partially discursive culture of enquiry.

The severe downturn in most developed economies since 2008 has generated renewed discussion of the relevance of Keynes's ideas among politicians and journalists. But regrettably there is little evidence that this new thinking has penetrated the mainstream of the economics profession. Furthermore, a return to Keynes means much more than the rehabilitation of a relatively neglected doctrine. The concept of uncertainty itself signals a retreat from the currently overwhelming obsessions with mathematical quantification, modeling and prediction. What would be involved is much than the rehabilitation of a single stream of thought. There is a need to reverse the priority of technique over substance in modern economics, and to bring the discipline back to its previous close intellectual engagement with other disciplines such as psychology, sociology, politics, history and philosophy.

To understand the current economic crisis we have to look at both economic history and the history of economic thought. To understand how markets work we have to dispense with empty proclamations of rationality and delve into psychology and elsewhere. To understand how economics has taken a wrong turn we have to appreciate work in the philosophy of economics and the relationship between economics and ideology. These unfashionable discourses have to be brought back into the centre of the economic curricula and rehabilitated as vital areas of enquiry. Unless mainstream economics takes heed of these warnings and proves its relevance for the understanding of the most severe crisis of the capitalist system since the 1930s, then it will be doomed to irrelevance as a practical tool for understanding and improving our economic condition.

Much greater dialogue is required between economics and the other social sciences. This is not only intrinsically vital, but it has become imperative because both economics and sociology have lost their preceding consensuses concerning the definitions and boundaries of their disciplines (Hodgson 2008). This suggests a need for some reorganization of the social 
sciences in universities. These needed curricular and organizational reforms will not come about easily. The task ahead is immense.

Such reorganization should place critical philosophical reflection at its apex. Notably both Knight and Keynes had significant training in philosophy. Consequently they could search for meaning and understanding without modeling or quantification. They were not exceptional but typical of the intellectual giants of our discipline: Adam Smith, Karl Marx, Alfred Marshall, Thorstein Veblen and Joseph Schumpeter all studied philosophy. Yet today most social scientists have little knowledge of the philosophy of science, and economists are no exception. Philosophy provides the conceptual tools to reflect upon the place and meaning of economic ideas and techniques. As noted above, it should be supplemented by knowledge of both the history of both economics and economies. Unless there is such extended and reutilized critical reflection in such an historical context, mainstream economics will remain a branch of applied mathematics and fall further down the slippery slope toward scientific and practical irrelevance.

\section{Notes}

1. This essay focuses on one of several other issues raised in Hodgson (2009) and uses some material from that essay. The author is very grateful for the valuable comments of Rick Adkisson, Mark Setterfield and anonymous referees on previous drafts of this essay.

2. I deliberately use the term "post-Keynesian" here rather than "Post Keynesian" because I refer literally to any economics after and accommodating Keynes, rather than any specific variety of Keynesianism.

3. The Boolean search condition is thus: (("uncertain" OR "uncertainty") AND ("Keynes" OR "Knight")).

4. Date of last available (in October 2009) appearance in JSTOR searchable database of academic journals (www.jstor.org).

5. A full and detailed textual analysis of the thousands of articles involved will have to await a much larger study with research assistance currently unavailable to this author.

6. It should be noted that precursors of the multiplier concept (without using that term) are found in works by Clark (1917) and others (see Shackle 1967: 264-6). The term "multiplying effect" appeared as early as 1921 in a U.S. Report of the President's Conference on Unemployment (Hodgson 2004: 311).

7. The data for ("multiplier" AND "Keynes") are not shown on the figure.

8. The phrase "investment volatility" has been used by both Keynesians and others. Its data (not illustrated here) show a rapid increase in usage after the 1970s, overtaking the concept of uncertainty in the 1990s.

9. See also Hodgson (2009). 
10. The notions of "formalism" and "formalization" require definition. Although the term has a broader meaning, I follow others in this context in associating it with the imposition of mathematical forms and models (Woo 1986, Chick 1998, Dow 1998, Krugman 1998).

11. The four journals were American Economic Review, the Economic Journal, the Journal of Political Economy and the Quarterly Journal of Economics, which are all among the ten represented in the preceding section.

12. Arrow later seemed to modify his view, with the publication of several milestone theoretical articles with discursive content.

13. Keynes wrote to Roy Harrod on 16 July 1938: "In economics . . to convert a model into a quantitative formula is to destroy its usefulness as an instrument of thought" (Keynes, 1973: 299). See also Moggridge (1992: 621-3).

14. See, for example, Baumol and Quandt (1985), Grandmont (1987), Kelsey (1988), Barnett et al. (1989), Baumol and Benhabib (1989), Brock and Malliaris (1989), Radzicki (1990), Brock et al. (1991), Benhabib (1992), Bullard and Butler (1993), Carrier (1993).

15. Note that the existence of uncertainty does not make prediction impossible. Knight (1921) saw the lumping together of assets under the umbrella of the firm as a reaction to uncertainty, and Keynes (1937) pointed out that people facing uncertainty generally fall back on regular patterns of behaviour, such as the imitation of others. But these (important and useful) predictions are imprecise, highly contingent and difficult to derive via a non-trivial mathematical model. Kregel's (1976) important consideration of modelling "in the face of uncertainty" is discussed later below.

16. Note my slight difference here with Lawson (1997), who emphasizes the problem of formalism alone. By contrast I have argued (Hodgson 2006, ch. 7) that some types of mathematical formalism - in particular heuristic models - are invulnerable to Lawson's critique. See also Sugden (2000).

17. Existing complexity discourse is no panacea. Its diverse content ranges from playful simulation to post-modernism and social constructivism, and it is sometimes of challengeable coherence or value (Horgan 1995). Nevertheless Colander is right to argue that economists should face up to real-world complexity.

18. The term "positivism" is used in a variety of different ways. Here I use it in a sense that is close to its original Comtean meaning, to describe a view of science that emphasises the role of prediction more than causal explanation (Lenzer 1998). In this sense there are strong positivist traits in Friedman's (1953) highly influential article.

19. For a topical comment on this see the article by Paul Krugman http://www.nytimes.com/2009/09/06/magazine/06Economic-t.html?_r=1 (accessed 1 October 2009).

20. See, for example, http://www.guardian.co.uk/business/2009/jun/01/larry-elliott-fantasyeconomics, http://www.prospect-magazine.co.uk/article details.php?id=10683/t blank, and http://blogs.ft.com/maverecon/2009/03/the-unfortunate-uselessness-of-most-state-of-the-artacademic-monetary-economics/, all accessed 27 July 2009. 
21. The notable recent conversion of the influential Richard Posner to Keynesianism, after his first reading of the General Theory, is of great importance. But Posner is an unusual and parttime academic who is also a judge. See http://www.tnr.com/article/how-i-became-keynesian (accessed 1 October 2009).

22. See Gunnar Myrdal's (1972: 6-7) own reminiscences on this era, as well as similar observations by other leading economists (Hodgson 2004: 383-6).

\section{References}

Arrow, Kenneth J. "Alternative Approaches to the Theory of Choice in Risk-Taking Situations," Econometrica 19(4), October 1951, pp. 404-37.

Backhouse, Roger E. "The Transformation of U.S. Economics, 1920-1960, Viewed through a Survey of Journal Articles." In The Transformation of American Economics: From Interwar Pluralism to Postwar Neoclassicism, Annual Supplement to Volume 30 of History of Political Economy, Edited by Mary S. Morgan and Malcolm H. Rutherford. Durham, North Carolina: Duke University Press, 1998, pp. 85-107.

Barnett, William A., John Geweke and, Karl Shell (eds) Economic Complexity: Chaos, Sunspots, Bubbles and Nonlinearity. Cambridge: Cambridge University Press, 1989.

Baumol, William J. and Jess Benhabib. "Chaos, Significance, Mechanism, and Economic Applications," Journal of Economic Perspectives 3(1), Winter 1989, pp. 77-105.

and Richard E. Quandt. "Chaos Models and Their Implications for Forecasting,” Eastern Economic Journal 11(1), January-March 1985, pp. 3-15.

Benhabib, Jess (ed.) Cycles and Chaos in Economic Equilibrium. Princeton, NJ: Princeton University Press, 1992.

Bhaskar, Roy. A Realist Theory of Science. Leeds: Leeds Books, 1975.

Blaug, Mark. "The Problems with Formalism: Interview with Mark Blaug," Challenge 41(3), May-June 1998, pp. 35-45.

"The Formalist Revolution or What Happened to Orthodox Economics After World War II?" In From Classical Economics to the Theory of the Firm: Essays in Honour of D. P. O'Brien edited by Roger E. Backhouse and John Creedy. Cheltenham: Edward Elgar, 1999, pp. 257-80.

“The Formalist Revolution of the 1950s." In A Companion to the History of Economic Thought, edited by Warren J. Samuels, Jeff E. Biddle and John B. Davis. Malden, MA and Oxford, UK: Blackwell, 2003, pp. 395-410.

Blinder, Alan (1990) 'Discussion', American Economic Review, 80, May, pp. 445-7.

Bloom, Allan. The Closing of the American Mind. New York: Simon and Schuster, 1988.

Bowen, Howard R. "Graduate Education in Economics," American Economic Review, Supplement, Graduate Education in Economics 43(4), Part 2, September 1953, pp. ii-xv+1223. 
Brock, William A. and A. G. Malliaris (eds) Differential Equations, Stability and Chaos in Dynamic Economics. Amsterdam: North-Holland, 1989.

David A. Hsieh and Blake LeBaron. Nonlinear Dynamics, Chaos, and Instability: Statistical Theory and Economic Evidence. Cambridge, MA: MIT Press, 1991.

Bullard, James and Alison Butler. "Nonlinearity and Chaos in Economic Models: Implications for Policy Decisions," Economic Journal 103(4), July 1993, pp. 849-67.

Caldwell, Bruce J. Beyond Positivism: Economic Methodology in the Twentieth Century. London: Allen and Unwin 1982.

Callahan, R. E. Education and the Cult of Efficiency. Chicago: University of Chicago Press, 1962.

Carrier, David. "Will Chaos Kill the Auctioneer?" Review of Political Economy 5(3), July 1993, pp. 299-320.

Chick, Victoria. "On Knowing One's Place: The Role of Formalism in Economics," Economic Journal 108(6), November 1998, pp. 1859-69.

Clark, John Maurice. "Business Acceleration and the Law of Demand: A Technical Factor in Economic Cycles,” Journal of Political Economy 25(1), March 1917, pp. 217-35.

Coase, Ronald H. "Interview with Ronald Coase," 17 September 1997. http://www.coase.org/coaseinterview.htm. Accessed November 16, 2008.

Cohen, Patricia. "Ivory Tower Unswayed by Crashing Economy," New York Times, March 5, 2009. http://www.nytimes.com/2009/03/05/books/05deba.html? r=1\&ref=arts. Accessed April 20, 2009.

Colander, David C. (ed.) The Complexity Vision and the Teaching of Economics. Cheltenham: Edward Elgar, 2000.

Colander, David C. The Making of a European Economist. Cheltenham: Edward Elgar, 2009.

Cornwall, John and Cornwall, Wendy. Capitalist Development in the Twentieth Century: An Evolutionary-Keynesian Analysis. Cambridge and New York: Cambridge University Press, 2001.

Crosby, Alfred W. The Measure of Reality: Quantification and Western Society, 1250-1600. Cambridge: Cambridge University Press, 1998.

Dasgupta, Partha. "Modern Economics and its Critics." In Fact and Fiction in Economics: Models, Realism and Social Construction, edited by Uskali Mäki, Cambridge: Cambridge University Press, 2002, pp. 57-89.

Davidson, Paul. Money and the Real World. London: Macmillan, 1972.

Davidson, Paul. "Is Probability Theory Relevant for Uncertainty? A Post Keynesian Perspective," Journal of Economic Perspectives, 5(1), Winter 1991, pp. 129-43.

Day, Richard H. "The Emergence of Chaos from Classical Economic Growth," Quarterly Journal of Economics 98, 1983, pp. 201-12.

Day, Richard H. and Wayne Shafer. "Keynesian Chaos," Journal of Macroeconomics 7, 1985, pp. 277-95.

Dow, Sheila C. "Editorial Note," Economic Journal 108(6), November 1998, pp. 1826-28. 
Friedman, Milton. "The Methodology of Positive Economics." In M. Friedman, Essays in Positive Economics. Chicago: University of Chicago Press, 1953, pp. 3-43.

Friedman, Milton. "Conversation with Milton Friedman.” In Conversations with Leading Economists: Interpreting Modern Macroeconomists, Edited by Brian Snowdon and Howard Vane. Cheltenham: Edward Elgar, 1999, pp. 122-44.

Goodwin, Richard M. "A Growth Cycle." In A Critique of Economic Theory, edited by E. K. Hunt and Jesse G. Schwartz. Harmondsworth: Penguin, 1972, pp. 442-9.

Goodwin, Richard M. Chaotic Economic Dynamics. Oxford: Oxford University Press, 1990.

Grandmont, Jean-Michel (ed.) Nonlinear Economic Dynamics. New York: Academic Press, 1987.

Greenberg, Daniel S. Science for Sale: The Perils, Rewards, and Delusions of Campus Capitalism. Chicago: University of Chicago Press, 2007.

Hicks, John R. Value and Capital: An Inquiry into Some Fundamental Principles of Economic Theory. Oxford: Oxford University Press, 1939.

Hodgson, Geoffrey M. The Evolution of Institutional Economics: Agency, Structure and Darwinism in American Institutionalism. London and New York: Routledge, 2004.

Hodgson, Geoffrey M. Economics in the Shadows of Darwin and Marx: Essays on Institutional and Evolutionary Themes. Cheltenham: Edward Elgar, 2006.

Hodgson, Geoffrey M. "Prospects for Economic Sociology," Philosophy of the Social Sciences 38(1), March 2008, pp. 133-49.

Hodgson, Geoffrey M. 'The Great Crash of 2008 and the Reform of Economics', Cambridge Journal of Economics, 33(6), November 2009, pp. 1205-21.

Hodgson, Geoffrey M. and Harry Rothman. "The Editors and Authors of Economics Journals: A Case of Institutional Oligopoly?” Economic Journal 109(2), February 1999, pp. F165F186.

Hoogduin, L. H. "On the Difference Between the Keynesian, Knightian and the "Classical" Analysis of Uncertainty and the Development of a More General Monetary Theory," De Economist 135(1), March 1987, pp. 52-65.

Horgan, John. "From Complexity to Perplexity," Scientific American 272(6), June 1995, pp. 104-9.

Kelsey, David "The Economics of Chaos or the Chaos of Economics." Oxford Economic Papers 40(1), March 1988, pp. 1-31.

Keynes, John Maynard. The General Theory of Employment, Interest and Money. London: Macmillan, 1936.

Keynes, John Maynard. “The General Theory of Employment," Quarterly Journal of Economics 51(1), February 1937, pp. 209-23.

Keynes, John Maynard. The Collected Writings of John Maynard Keynes, Vol. XIV, The General Theory and After, Part II: Defence and Development. London: Macmillan, 1973.

Kirp, David L. Shakespeare, Einstein, and the Bottom Line: The Marketing of Higher Education. Cambridge, MA: Harvard University Press, 2003.

Knight, Frank H. Risk, Uncertainty and Profit. New York: Houghton Mifflin, 1921. 
Kregel, Jan A. "Economic Methodology in the Face of Uncertainty: The Modelling Methods of Keynes and the Post-Keynesians." Economic Journal 86(2), June 1976, pp. 209-25.

Krueger, Anne O. et al. (1991) 'Report on the Commission on Graduate Education in Economics', Journal of Economic Literature, 29(3), September, pp. 1035-53.

Krugman, Paul R. "Two Cheers for Formalism," Economic Journal 108(6), November 1998, pp. 1829-36.

Lawson, Tony. "Uncertainty and Economic Analysis," Economic Journal 95(4), December 1985, pp. 909-27.

Lawson, Tony. Economics and Reality. London and New York: Routledge, 1997.

Leijonhufvud, Axel. On Keynesian Economics and the Economics of Keynes: A Study in Monetary Theory. London: Oxford University Press, 1968.

Lenzer, Gertrud (ed.) Auguste Comte and Positivism. New Brunswick, NJ: Transaction, 1998.

Leontief, Wassily W. Letter in Science, No. 217, 9 July 1982, pp. 104, 107.

Lucas, Robert E., Jr. "Understanding Business Cycles." In Stabilization of the Domestic and International Economy, edited by Karl Brunner and Allan H. Metzler. Amsterdam: NorthHolland, 1977, pp. 7-29.

Lutz, Frank W. and Robert W. Field. Business Valuing in Academia: The American University as a Center for Profit or Inquiry? Higher Education 36(4), December 1998, pp. 383-419.

McCloskey, Donald N. Knowledge and Persuasion in Economics. Cambridge and New York: Cambridge University Press, 1994.

Mirowski, Philip. More Heat Than Light: Economics as Social Physics, Physics as Nature's Economics. Cambridge: Cambridge University Press, 1989.

Moggridge, Donald E. Maynard Keynes: An Economist's Biography. London: Routledge, 1992.

Myrdal, Gunnar. Against the Stream: Critical Essays in Economics. New York: Pantheon Books, 1972.

Quine, Willard van Orman. From a Logical Point of View. Cambridge, MA: Harvard University Press, 1953.

Radzicki, Michael J. "Institutional Dynamics, Deterministic Chaos, and Self-Organizing Systems.” Journal of Economic Issues 24(1), March 1990, pp. 57-102.

Ravetz, Jerry. "Economics as an Elite Folk Science: The Suppression of Uncertainty" Journal of Post Keynesian Economics 17(2), Winter 1994-95, pp. 165-84.

Rosser, J. Barkley, Jr. From Catastrophe to Chaos: A General Theory of Economic Discontinuities. Dordrecht: Kluwer, 1991.

Runde, Jochen H. "Clarifying Frank Knight's Discussion of the Meaning of Risk and Uncertainty." Cambridge Journal of Economics 22(5), September 1998, pp. 539-46.

Shackle, George L. S. The Years of High Theory: Invention and Tradition in Economic Thought 1926-1939. Cambridge: Cambridge University Press, 1967. 
Shiller, Robert J. The Subprime Solution: How Today's Global Financial Crisis Happened, and What to Do about It. Princeton NJ: Princeton University Press, 2008.

Stigler, George J., Stephen M. Stigler and Claire Friedland. "The Journals of Economics." Journal of Political Economy 105(2), 1995, pp. 331-59.

Sugden, Robert. "Credible Worlds: The Status of Theoretical Models in Economics." Journal of Economic Methodology 7(1), March 2000, pp. 1-31.

Veblen, Thorstein B. The Higher Learning in America: A Memorandum on the Conduct of Universities by Business Men. New York: Huebsch, 1918.

Weintraub, E. Roy. How Economics Became a Mathematical Science. Durham, NC: Duke University Press2002.

Woo, Henry K. H. What's Wrong with Formalization in Economics?An Epistemologhical Critique. Newark, CA: Victoria Press, 1986. 
Journal

American Economic Review

Econometrica

Economic Journal

Economica

Journal of Political Economy

Oxford Economic Papers

Quarterly Journal of Economics

Review of Economic Studies

Review of Economics and Statistics

Southern Economic Journal
Date of first appearance

1911

1933

1891

1921

1892

1938

1886

1933

1919

1933
Date of last appearance

2006

2006

2003

2003

2003

1997

2003

2005

2003

2005

Table 1: Leading Anglo-American Journals of Economics in Existence Since 1940

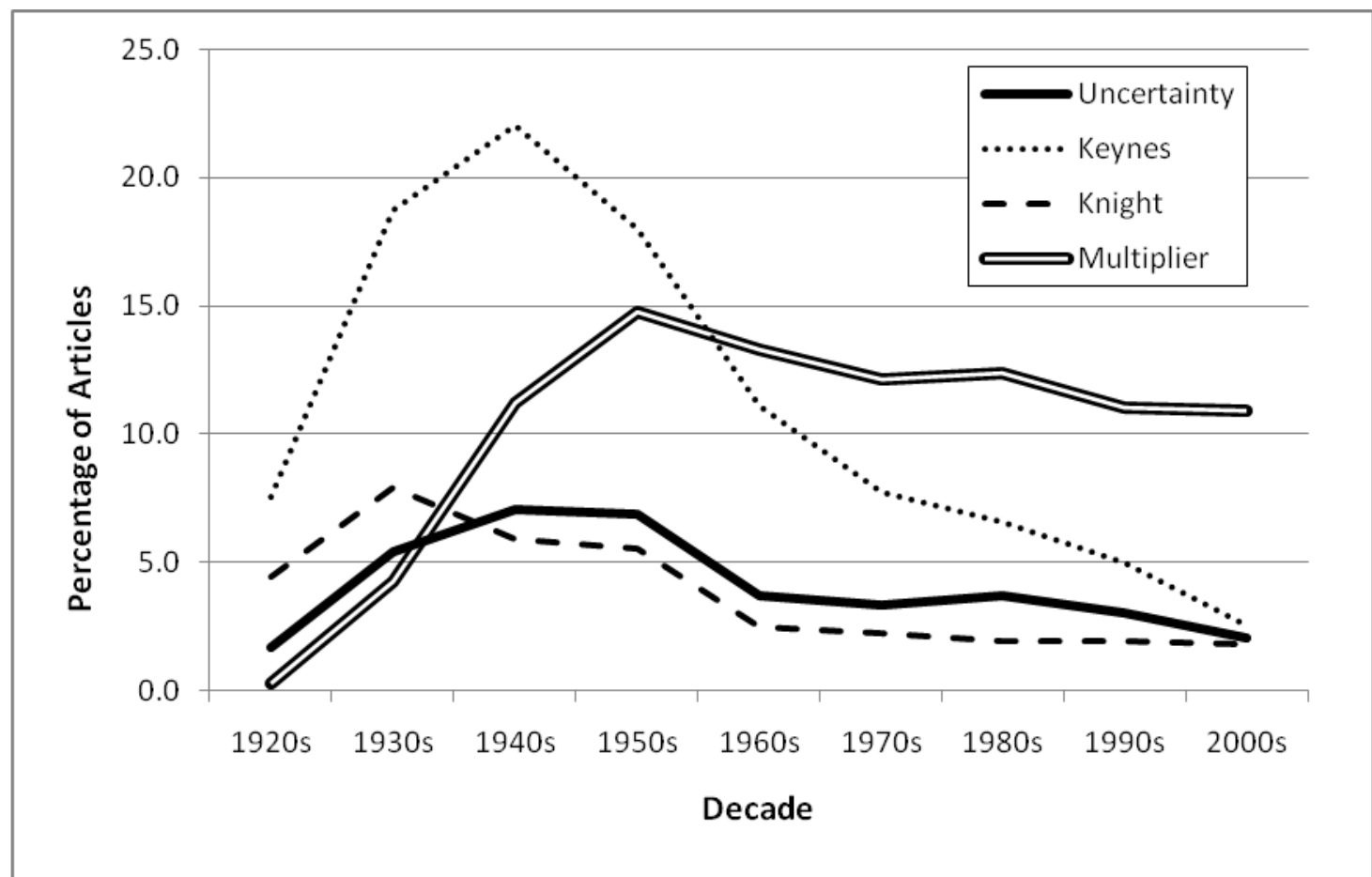

Figure 1: Percentage of Articles Citing to Keynes or Knight, Estimated Percentage of Articles Containing the Knight-Keynes Concept of Uncertainty, and Percentage of Articles Mentioning the Multiplier 


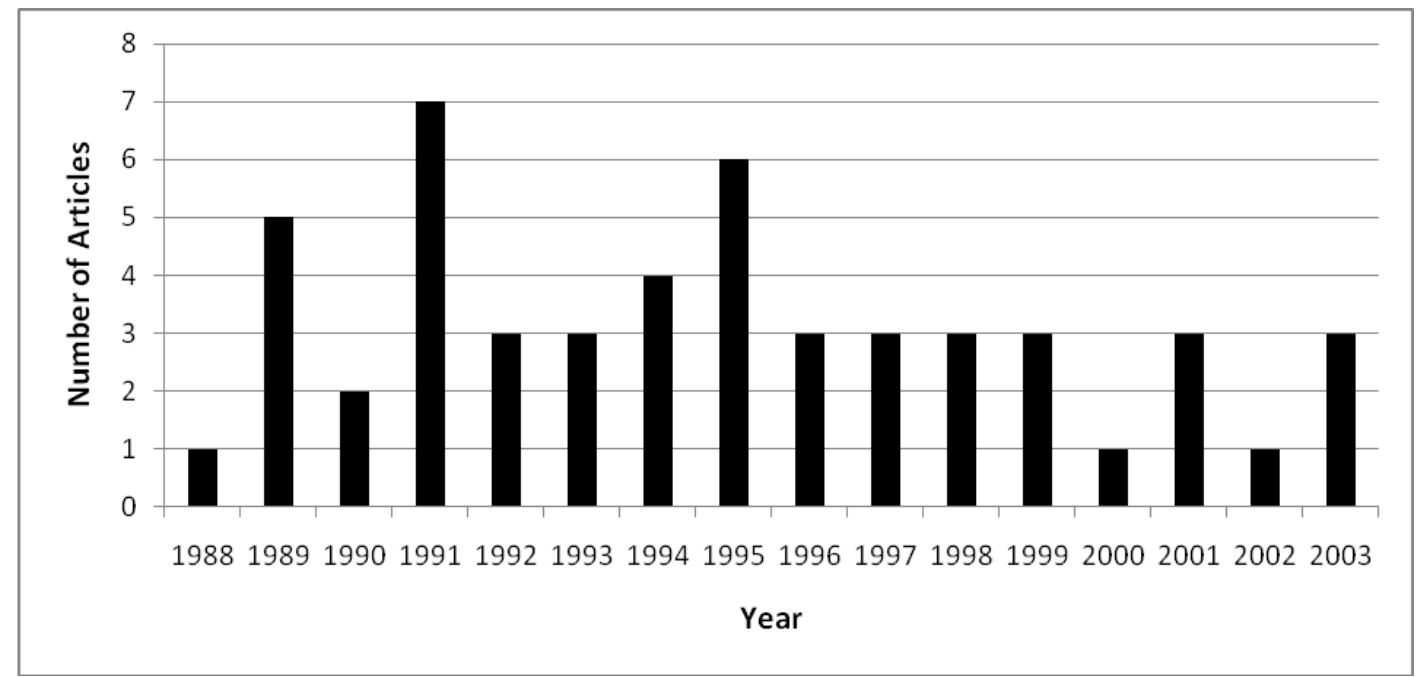

Figure 2: Number of Articles Containing the Term "Chaos Theory" in all JSTOR Journals of Economics, 1988-2003 